East African Medical Journal Vol. 87 No. 3 March 2010

ASSESSMENT OF DIABETIC RETINOPATHY IN NEWLY DIAGNOSED BLACK KENYAN TYPE 2 DIABETICS

H.E. Nkumbe, MD, MMed (Ophth.), MSc, DCH\&TM, FRIPH, SALFAEye Project Antananarivo, P.O. Box3825, Antananarivo 105, Madagascar, K. H. M. Kollmann, MBChB, MD, MMed (Ophth.), Dip. Trop. Med. \& Med. Parasitol, MBA (Health Care Management), Department of Ophthalmology, College of Health Sciences, University of Nairobi, P.O. Box 1967600202, Nairobi, Kenya and H.C. Gaeckle, MBChB, MD, MMed. (Ophth.) Ludwigstr. 17,0-89231 Neu-Ulm, Germany

Request for reprints to: Dr. H.E. Nkumbe, P.O. Box 3825, Antananarivo 105, Madagascar

\title{
ASSESSMENT OF DIABETIC RETINOPATHY IN NEWLY DIAGNOSED BLACK KENYAN TYPE 2 DIABETICS
}

\author{
H.E. NKUMBE, K. H. M. KOLLMANN and H.C. GAECKLE
}

\begin{abstract}
Objective: To determine the prevalence and pattern of diabetic retinopathy in newly diagnosed black African patients with type 2 diabetes mellitus and the associated risk factors.

Design: Cross-sectional hospital-based study.

Setting: Eye clinic of Kenyatta National Hospital, Nairobi, Kenya.

Subjects: Africans aged 20 years and above with newly diagnosed type 2 diabetes mellitus of up to 12 months duration.

Results: One hundred and forty one eyes of 71 patients were included in this study, while slides of 92 eyes of 65 patients were of good enough quality for evaluation. The mean duration of diabetes was 11.7 weeks (SD 16.6) and 11.3 (SD 10.1) in men and women respectively. Overall, the prevalence of diabetic retinopathy and clinically significant macula oedema was $30.4 \%$ and $8.7 \%$ respectively. There was a positive association between diabetic retinopathy and systolic blood pressure.

Conclusion: The prevalence of diabetic retinopathy in newly diagnosed Africans with type 2 diabetes in Kenya is very high. This suggests longstanding undiagnosed diabetes.
\end{abstract}

\section{INTRODUCTION}

About 285 million people are affected by diabetes mellitus (DM) worldwide, including 519,100 in Kenya alone (1).

Diabetic retinopathy (DR), one of the major complications of DM and the most important ocular complication, is a serious public health problem worldwide. In the United States and the United Kingdom, epidemiological data suggest that the leading cause of blindness in working age adults is DR $(2,3)$. After 20 years, virtually all type 1 and more than $60 \%$ of all type 2 diabetics have some retinopathy (2). In developing countries especially in Africa, though, there is a paucity of information on the contribution to visual loss by diabetic retinopathy (4).

Previous hospital-based cross sectional studies carried out in Kenya had put the prevalence of DR among diabetics at $18.3 \%$ and $49.9 \%$ in a rural and an urban setting respectively. A significant number of these patients presented with advanced stages of retinopathy $(5,6)$.

The prevalence of diabetic retinopathy in newly diagnosed Africans with type 2 diabetes and its progression are not well documented. The United Kingdom Prospective Diabetes Study (UKPDS), by far the largest study on the prevalence of retinopathy in newly diagnosed diabetics, showed that diabetic retinopathy was present in 39\% of men and 35\% of women (7) in this group of patients. This is much higher than data from other studies on diabetics of European $(8,9)$, Indian (10) African $(11,12)$ and Taiwanese (13) origin. In these studies, the prevalence of diabetic retinopathy in newly diagnosed patients with type 2 diabetes was $30 \%, 10.2 \%, 6.7 \%, 16 \%, 24.8 \%$ and $28.3 \%$ respectively.

The aim of this study was to provide baseline data on the prevalence and pattern of diabetic retinopathy in newly diagnosed Black Africans with type 2 diabetes in Kenya using fundus photographic colour slides.

Colour fundus photographs were used in this study because they have been shown to be either superior $(7,14,15)$ or comparable $(16-19)$ to an ophthalmological assessment inscreening for diabetic retinopathy. Most published studies, including all those carried out in the East African region have used ophthalmoscopy with or without slit lamp biomicroscopy to diagnose diabetic retinopathy. It is however recognised that even in the hands of a skilled examiner 1 to 3 microaneurysms can easily be missed on ophthalmoscopy (7) and at least one microaneurysm is needed for the diagnosis of diabetic retinopathy (14). 


\section{MATERIALS AND METHODS}

This was a cross-sectional hospital-based study of all newly diagnosed black Africans with type 2 diabetes attending the diabetes clinic at Kenyatta National Hospital, Nairobi, between May $1^{\text {st }} 2001$ and February $28^{\text {th }} 2002$. African patients with a diagnosis of type 2 diabetes of not more than 12 months duration were eligible for inclusion in the study.

Diabetes was defined based on the 1999 classification published by WHO (20), while diabetic retinopathy was defined according to the modified Airlie House ETDRS classification (21).

Subjects visiting the medical diabetes clinics were recruited after they had consulted the physician in the diabetes clinic and written informed consent for participation in the study had been obtained.

Information on patient characteristics (age, sex, height, weight), medicalhistory (hypertension, duration of diabetes as well as management) and biochemical investigations (random blood sugar and $\mathrm{HBA}_{1} \mathrm{C}$ ) was obtained. Two blood pressure measurements were taken with a mercury sphygmomanometer at 5 minutes intervals after the patient had rested on a chair for 30 minutes and the arithmetic mean calculated. Presenting visual acuity was taken using a Snellen or an illiterate E chart. A complete examination of the anterior segments using the slit lamp biomicroscope (Haag Streit 900) then followed.

Both eyes were dilated with $1 \%$ tropicamide instilled at 5 minute intervals until both eyes were well dilated for fundus examination and photography. Indirect ophthalmoscopy was done with a binocular indirect ophthalmoscope and a 200 loupe, and slit lamp biomicroscopy with a 900 loupe.

Fundus photographs were done in all eyes recruited for the study using a Canon CF-60U fundus camera as follows: 2 stereoscopic maculaoptic disc 30 degrees and two stereoscopic maculacentred 60 degrees colour fundus photographs of each eye were made. Fluorescein angiography (FLA) was done in case of diabetic retinopathy with clinically significant macula edema (CSME) proliferative diabetic retinopathy or to evaluate unexplained visual loss. ASA 100 Kodak colour slide films were used for fundus photography, while ASA 400 Kodak black and white films were used for fluorescein angiography.

Stereoscopic examination of stereo pairs of slides was done using monocular illuminated slide viewers (UNOMAT D-100 B), for individual viewing (22), and a slide projector for group viewing by all three investigators.

All lesions observed in the photographs (microaneurysms, retinal haemorrhages, hard exudates, cotton wool spots, IRMAs, venous beading, neovascularisations etc.) were graded and used to classify retinopathy using the standard ETDRS photographs and criteria.

All photographs were taken by the principal investigator, while diagnoses and classification of retinopathy required agreement by all three investigators.

Data capture was done using Staview $®$ statistical package and analysis using Intercooled Stata version 9.0. Student t-test and Pearson's chi-square were used to test associations as appropriate.

\section{RESULTS}

One hundred and forty one eyes of 71 patients were included in this study. However, only slides of 92 eyes of 65 patients were of good enough quality for evaluation. The reasons for poor slide quality were: accidental opening of the fundus camera by eye clinic colleagues, media opacities or poor processing of slides in the laboratory. Fluorescein angiography was done in two patients. In the first case, it was to confirm whether the patient had severe NPDR or mild PDR. In the second, it was used to confirm the presence of CSME.

In all, $42 \%$ of our study subjects were male. Table 1 summarises the characteristics of study subjects.

Table 1

Comparison between male and female participants

\begin{tabular}{|c|c|c|c|c|c|c|c|}
\hline & \multirow[b]{2}{*}{ No. } & \multicolumn{2}{|l|}{ Men } & \multicolumn{3}{|c|}{ Women } & \multirow[b]{2}{*}{ P-value } \\
\hline & & Mean & SD & No. & Mean & SD & \\
\hline Age at diagnosis, (years) & 29 & 51.7 & 12.7 & 29 & 51.2 & 11.6 & 0.88 \\
\hline Duration of diabetes (weeks) & 24 & 11.7 & 16.6 & 30 & 11.3 & 10.1 & 0.92 \\
\hline Systolic BP, mm Hg & 23 & 128.3 & 4.6 & 31 & 129.9 & 4.7 & 0.81 \\
\hline Diastolic BP, mm Hg & 23 & 79.6 & 2.9 & 31 & 83.4 & 3.5 & 0.43 \\
\hline Body mass index, $\mathrm{Kgm}^{-2}$ & 23 & 26.1 & 4.5 & 30 & 27.8 & 4.7 & 0.18 \\
\hline Random Blood Sugar, mmoll-1 & 27 & 12.0 & 7.4 & 34 & 11.0 & 6.1 & 0.55 \\
\hline $\mathrm{HBA}_{1} \mathrm{C}(\%)$ & 18 & 8.1 & 1.8 & 15 & 8.5 & 2.3 & 0.54 \\
\hline
\end{tabular}


The prevalence of diabetic retinopathy in men and women was $33 \%$ and $28 \%$ respectively $(P=0.15)$, while the overall prevalence was $30.4 \%$. Diabetic retinopathy was unilateral in three patients $(6.5 \%)$ and bilateral in 11 (23.9\%). Table 2 below shows the retinopathy status of examined eyes.
Four out of 46 patients $(8.7 \%$ ) had clinically significant macula edema (CSME). The mean duration of diabetic retinopathy in patients with CSME was 27 weeks (SD 10.5), while it was 8.8 weeks in those without CSME (SD 9.4). This suggests a very strong association between duration of diabetes and CSME $(\mathrm{P}=0.02)$.

Table 2

Eyes of diabetic people with specified retinopathy level

\begin{tabular}{lcc}
\hline & \multirow{2}{*}{ Eyes } \\
& No. $\quad(\%)$ \\
\hline Normal & 67 & 72.8 \\
Mild non-proliferative diabetic retinopathy & 5 & 5.4 \\
Moderate non proliferative diabetic retinopathy & 14 & 15.2 \\
Severe non proliferative diabetic retinopathy & 2 & 2.2 \\
Early proliferative diabetic retinopathy & 1 & 1.1 \\
High risk proliferative diabetic retinopathy & 3 & 3.3 \\
\hline Total & 92 & 100 \\
\hline
\end{tabular}

Figure 1

Mild non proliferative diabetic retinopathy

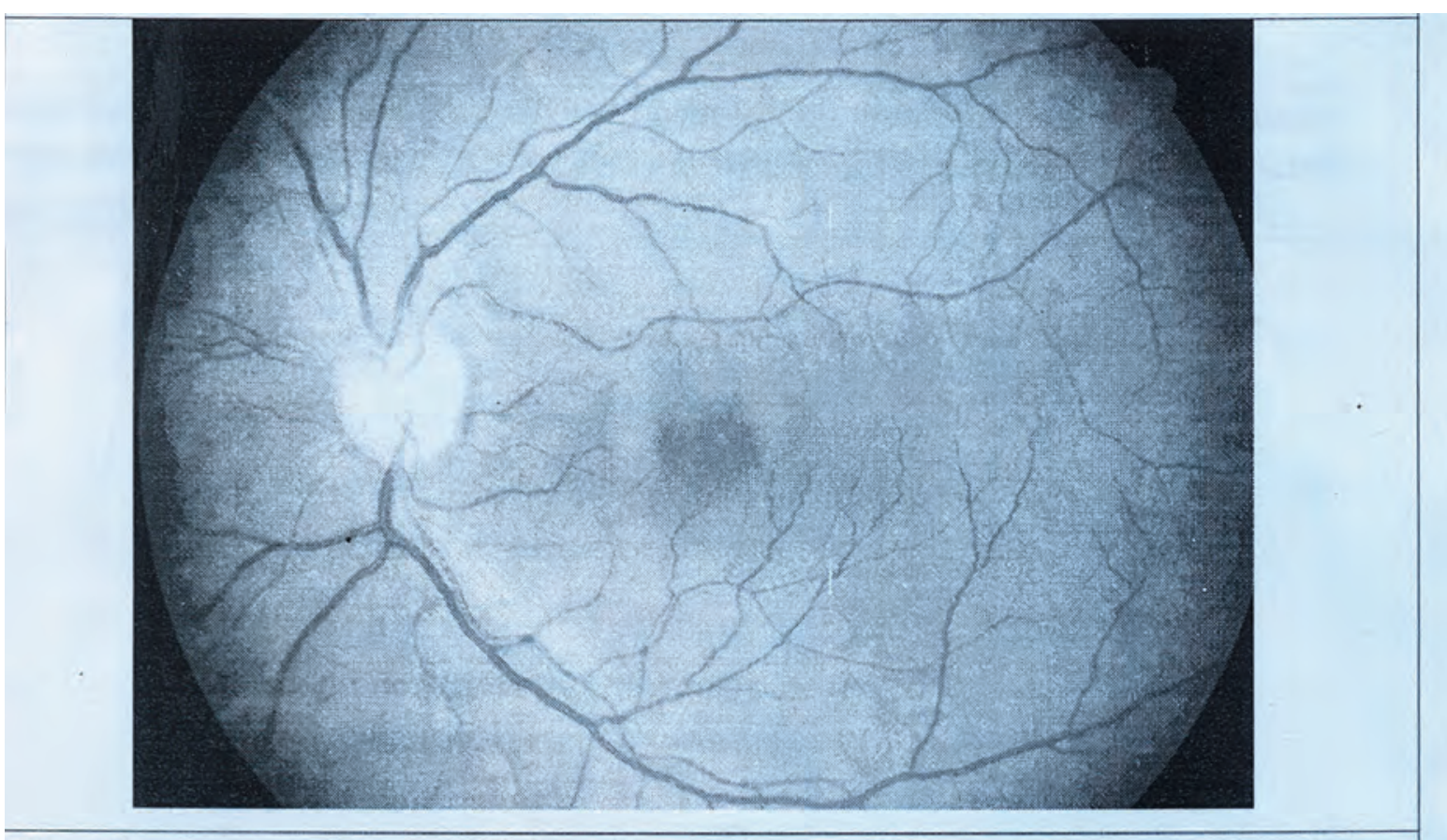

Case summary: 45 year old female with known diabetes of two weeks duration. Note the microaneurysm $1 / 2$ disk diameter supero-nasal to the fovea and just above the kink in the supero-temporal branch of the retinal artery. 
Figure 2

High risk proliferative diabetic retinopathy

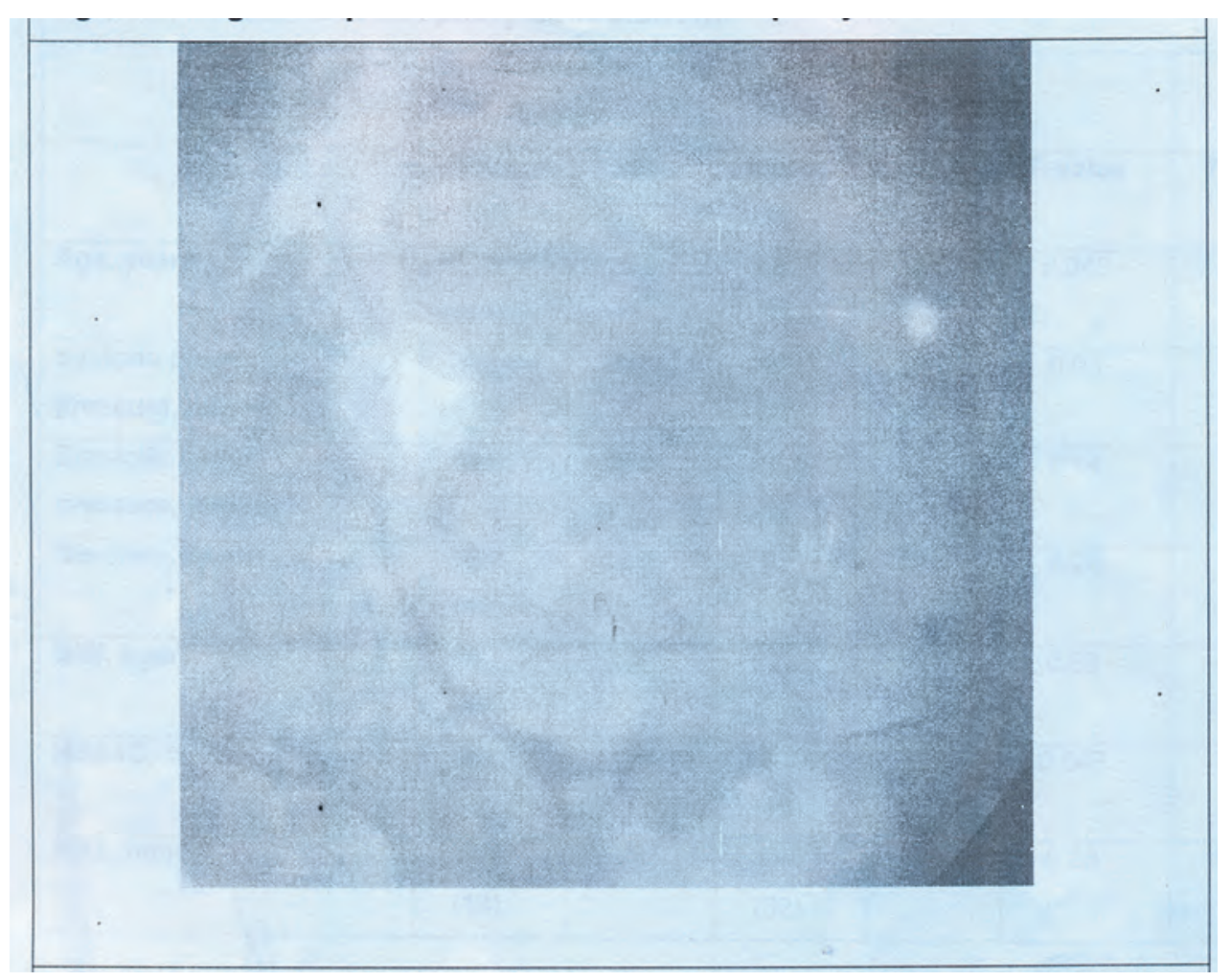

Case summary: 52 year old male with bilateral proliferative diabetic retinopathy. Note neovasuclarisation at the disc and elsewhere, fibro-vascular tractional bands and vitreous haemorrhage

Table 3

Diabetic retinopathy associations

\begin{tabular}{|c|c|c|c|c|c|c|}
\hline & \multicolumn{2}{|c|}{$\begin{array}{c}\text { Retinopathy } \\
\text { Present }\end{array}$} & \multicolumn{2}{|c|}{$\begin{array}{c}\text { Retinopathy } \\
\text { Absent }\end{array}$} & \multirow[b]{2}{*}{ P-value } & \multirow[b]{2}{*}{ Total } \\
\hline & $\begin{array}{l}\text { Mean } \\
\text { (n) }\end{array}$ & SD & $\begin{array}{l}\text { Mean } \\
\text { (n) }\end{array}$ & SD & & \\
\hline Age (years) & $57.2(11)$ & 15.6 & $48.7(29)$ & 10.0 & 0.048 & 40 \\
\hline $\begin{array}{l}\text { Systolic blood } \\
\text { pressure, mm } \mathrm{Hg}\end{array}$ & $140.4(12)$ & 29.6 & $122.1(27)$ & 19.3 & 0.03 & 39 \\
\hline $\begin{array}{l}\text { Diastolic blood } \\
\text { pressure, mm } \mathrm{Hg}\end{array}$ & 84.6 & 15.9 & $76.9(27)$ & 14.2 & 0.14 & 39 \\
\hline Duration (weeks) & $13.8(12)$ & 12.5 & $9.7(27)$ & 10.0 & 0.28 & 39 \\
\hline BMI, $\mathrm{kgm}^{-2}$ & $26.5(14)$ & 1.4 & $27.1(27)$ & 4.0 & 0.68 & 41 \\
\hline $\mathrm{HBA}_{1} \mathrm{C}, \%$ & $7.2(9)$ & 1.5 & $8.9(16)$ & 2.2 & 0.047 & 25 \\
\hline RBS, mmol1 ${ }^{-1}$ & $11.9(14)$ & 5.6 & $11.5 \quad(32)$ & 7.5 & 0.88 & 46 \\
\hline
\end{tabular}




\section{DISCUSSION}

Colour fundus photographs have been shown to be either superior $(7,14,15)$ or comparable (16-19) to an ophthalmological assessment in screening for diabetic retinopathy. Most studies, including all those carried out in the East African region have used ophthalmoscopy with or without slit lamp biomicroscopy to diagnose diabetic retinopathy. It is however recognised that even in the hands of a skilled examiner 1 to 3 microaneurysms can easily be missed on ophthalmoscopy (7) and at least one microaneurysm is needed for the diagnosis of diabetic retinopathy (14). Besides, the presence of microaneurysms as well as their absolute count alone are good predictors of the progression and severity of diabetic retinopathy respectively (23-25). Hence, studies in which diabetic retinopathy is diagnosed by ophthalmoscopy alone are likely to underestimate the true prevalence.

For the first time in the East African region, this study graded diabetic retinopathy using non simultaneous stereoscopic fundus photographs. ETDRS standard photographs and guidelines were used for standardisation and reproducibility of results (21).

One hundred and forty one eyes of 71 patients were examined in this study. However, only slides for 92 eyes of 46 patients existed in stereo pairs and fulfilled the quality requirements for inclusion in the study.

Of the newly diagnosed type 2 diabetic patients whose fundus photographs were analysed, 30.4\% were found to have diabetic retinopathy of one form or the other. Of these, more than $4 \%$ had proliferative diabetic retinopathy in at least one eye. This compares slightly favourably with the United Kingdom Prospective Diabetes Study (UKPDS), in which fundus photographic assessment of both eyes of newly diagnosed patients with type 2 diabetics revealed a prevalence of diabetic retinopathy of $39 \%$ in the male population and $35 \%$ of the female population (7).

The prevalence of retinopathy in newly diagnosed type 2 diabetics was $6.7 \%$ in India (10), $10.2 \%$ in the Beaver Dam Eye Study (9), 28.3\% in Taiwan (13), 30\% in Sweden (8), 16\% in Egypt (11) and $24.8 \%$ in Guinea (12). It is difficult to compare the above studies because the definition of "newly diagnosed type 2 diabetic" is not standardised and different methods were used in detecting retinopathy (indirect ophthalmoscopy with or without slit lamp biomicroscopy on the one hand and stereoscopic fundus photographs on the other hand).

There was a strong positive association ( $\mathrm{p}=$ 0.03 ) between diabetic retinopathy and systolicblood pressure in keeping with a previous study carried out in rural Kenya (6). However, we did not find any association between diastolic blood pressure and the presence of diabetic retinopathy $(\mathrm{p}=0.09)$.

Hypertension is recognised as a risk factor for the development and progression of diabetic retinopathy $(26,13)$, and $20.6 \%$ of our newly diagnosed patients with type 2 diabetes mellitus were equally being treated for hypertension. In blacks, the risk for retinopathy has been noted to increase with systolic blood pressure (26). This underscores the importance of having blood pressures measured regularly and accurately in all new diabetic patients and ensuring adequate control of pressures if the early onset or quick progression of retinopathy is to be averted.

The mean duration of diabetes was 11.5 weeks and no association was found between duration of diabetes and retinopathy. It is believed that undiagnosed type 2 diabetes mellitus may occur 4-12 years before its clinical diagnosis and that diabetes may be present for five years before the onset of retinopathy $(10,27)$. Undiagnosed type 2 is thus not a benign condition. The unknown duration (years) of undiagnosed diabetes in our patients is likely to be a more important contributory factor to retinopathy than the known (weeks) duration of diagnosis. This is further supported by the fact that patients with diabetic retinopathy were older than those without $(\mathrm{P}=0.048)$.

The normal range for $\mathrm{HbA}_{1} \mathrm{C}$ in our laboratory was $4.8-7.8 \%$. The mean value was $8.3 \%$ for all patients and $60.6 \%$ of all patients had $\mathrm{HbA}_{1}$ Cgreater than $7.8 \%$. There was a slight tendency towards normalisation of $\mathrm{HbA}_{1} \mathrm{C}$ with duration of diabetes, which was not statistically significant.

Poor glycaemic control is known to be the main risk factor for diabetic retinopathy. Sixty point six per cent of our patients with newly diagnosed type 2 diabetes mellitus have an increased risk of developing diabetic retinopathy if their $\mathrm{HbA}_{1} \mathrm{C}$ is anything to go by. This includes those with diabetic retinopathy on diagnosis and could explain the $49.8 \%$ prevalence of diabetic retinopathy found among all diabetics attending our clinic in a previous study (5).

CSME was present in at least one eye of $8.2 \%$ of our patients. There was no association between CSME and hypertension or $\mathrm{HbA}_{1} \mathrm{C}$. However, there was a strong association between CSME and duration of diabetes. This association was statistically significant.

The prevalence of diabetic retinopathy in newly diagnosed diabetics in this study was 30.4\%, with $8.2 \%$ having vision-threatening retinopathy. In our study, $60.6 \%$ of the patients are at increased risk of developing retinopathy because of possible longstanding undiagnosed diabetes mellitus. This underscores the need for intensified efforts for early diagnosis of type 2 diabetes mellitus and careful fundus biomicroscopic examination of all newly diagnosed type 2 diabetics in our set-up. 


\section{REFERENCES}

1. InternationalDiabetes Federation. Diabetes atlas 2010. http://www.eatlas.idf.org. Accessed December 2009.

2. Mohamed, Q., Gillies, M.C. and Wong, T.Y. Management of diabetic retinopathy: a systematic review. JAMA. 2007; 298: 902-916.

3. Bunce, C. and Wormald, R. Causes of blind certifications in England and Wales: April 1999-March 2000. Eye. 2008; 22: 905-911.

4. Kalk, W.J., Joannou, J., Ntsepo, S., et al. Ethnic differences in the clinical and laboratory associations with retinopathy in adult onset diabetes: studies in patients of African, European and Indian origins. J. Intern. Med. 1997; 241: 31-37.

5. Kariuki, M.M. The prevalence, pattern and associations of diabetic retinopathy among Black African diabetics attending the medical diabetes clinic at Kenyatta National Hospital. MMed Dissertation. University of Nairobi. 1999.

6. Githeko, A.K., Kollmann, K.H.M., Adala, H.S. and Courtright, P. Prevalence, pattern and risk factors of diabetic retinopathy among diabetic patients attending rural health institutions in central Kenya. East Afr. J. Ophthalm. 2007; 13: 2.

7. Kohner, E.M., Aldington, S.J., Stratton, I.M., et al. United Kingdom Prospective Diabetes Study, 30: diabetic retinopathy at diagnosis of non-insulin dependent diabetes mellitus and associated risk factors. Arch. Ophthalmol. 1998; 116: 297-303.

8. Agardh, E. Eye complications in diabetes. According to new criteria patients with diabetes should have ophthalmological examination at the time of diagnosis (Ogonkomplikationer vid diabetes. Diabetiker enligt nya kriterier bor ogonundersokas vid diagnos). Lakartidningen. 1998; 95: 5640-5642.

9. Klein, R., Klein, B.E., Moss, S.E. and Linton, K.L. The Beaver Dam Eye Study. Retinopathy in adults with newly discovered and previously diagnosed diabetes mellitus. Ophthalmology. 1992; 99: 58-62.

10. Ramachandran, A., Snehalatha, C., Vijay, V. and Viswanathan, M. Diabetic retinopathy at the time of diagnosis of NIDDM in south Indian subjects. Diabetes Res. Clin. Pract. 1996; 32: 111-114.

11. Herman, W.H., Aubert, R.E., Engelgau, M.M., et al. Diabetes mellitus in Egypt: glycaemic control and microvascular and neuropathic complications. Diabet. Med. 1998; 15: 1045-1051.

12. Balde, N.M., Kaba, M.L., Balde, M.D., et al.Frequency of diabetic microangiopathy in newly diagnosed diabetes mellitus in Conakry: late diagnosis and lack of screening. Dakar Med. 2007; 52: 165-170.

13. Chang, C.J., Fu, C.C., Chen, M.S., et al. A comparison of newly and previously diagnosed diabetics in Taiwan. J. Formos. Med. Assoc. 1990; 89: 264-269.

14. Kinyoun, J.L., Martin, D.C., Fujimoto, W.Y. and Leonetti, D.L.Ophthalmoscopy versus fundus photographs for detecting and grading diabetic retinopathy. Invest. Ophthalmol Vis. Sci. 1992; 33: 1888-1893.
15. Diamond, J.P., McKinnon, M., Barry, C., et al. Nonmydriatic fundus photography: a viable alternative to fundoscopy for identification of diabetic retinopathy in an Aboriginal population in rural Western Australia? Aust. N.Z.J. Ophthalmol. 1998; 26: 109-115.

16. Joannou, J., Kalk, W.J., Mahomed, I., et al.Screening for diabetic retinopathy in South Africa with 60 degrees retinal colour photography. J. Intern. Med. 1996; 239: 43-47.

17. Pugh, J.A., Jacobson, J.M., Van Heuven, W.A., et al. Screening for diabetic retinopathy. The wide-angle retinal camera. Diabetes Care. 1993; 16: 889-895.

18. Lee, V.S., Kingsley, R.M., Lee, E.T., et al. The diagnosis of diabetic retinopathy. Ophthalmoscopy versus fundus photography. Ophthalmology. 1993; 100: 15041512.

19. Verhoeven, S., van Ballegooie, E., Crijns, H., et al. Is fundus photography useful in screening for diabetic retinopathy in patients with type II diabetes mellitus? (Is fundusfotografie zinvol bij de screening op diabetische retinopathie bij patienten met diabetes mellitus type II?) Ned-Tijdschr-Geneeskd. 1993; 137: 1713-1717.

20. Definition, Diagnosis and Classification of Diabetes Mellitus and its Complications, Report of a WHO consultation. Part 1: Diagnosis and Classification of Diabetes Mellitus. WHO/NCD/NCS/99.2. World Health Organisation, Geneva 1999.

21. Early treatment Diabetic Retinopathy Study Research Group, Grading Diabetic Retinopathy from Stereoscopic Color Fundus Photographs - An Extension of the Modified Airlie House Classification: ETDRS Report Number 10. Ophthalmology. 1991; 98 Suppl: $786-806$.

22. Saine, P.J. and Tyler, M.E. Ophthalmic Photography. A textbook of Retinal Photography, Angiography and Electronic Imaging. Butterworth Heinemann. 1996.

23. Kohner, E.M., Stratton, I. M., Aldington, S.J., Turner, R.C. and Matthews, D.R. Microaneurysms in the development of diabetic retinopathy (UKPDS 42). UK Prospective Diabetes Study Group Diabetologia. 1999; 42: 1107-1112.

24. Klein, R., Meuer, S.M., Moss, S.E. and Klein, B.E. The relationship of retinal microaneurysm counts to the 4-year progression of diabetic retinopathy. Arch. Ophthalmol. 1989; 107: 1780-1785.

25. Kohner,E.M.andSieightholm,M.Does microaneurysm count reflect severity of early diabetic retinopathy? Ophthalmology. 1986; 93: 586-589.

26. Harris, E.L., Feldman, S., Robinson, C.R., Sherman,S. and Georgopoulos, A. Racial differences in the relationship between blood pressure and risk of retinopathy among individuals with NIDDM. Diabetes Care. 1993; 16: 748-754.

27. Harris, M.I., Klein, R., Welborn, T.A. and Knuiman, M.W. Onset of NIDDM occurs at least 4-7 years before clinical diagnosis. Diabetes Care. 1992; 15: 815-819. 